\title{
PENSAR LA NARRATIVA LATINOAMERICANA
}

\author{
Aimée Gonzalez Bolaños
}

RESUMO: With two main questions in mind - «the hegemonic tendencies of the Latin-American narrative in its relationship with the high modernity culture» and «the development of the Latin America narrative poetics in its modernization process, from the late 20 's to our times» - this paper intends to offer a diacronic vision of narrative, searching the key-points for a reflexive interpretation of the polemical topic of our identity in writing. Confrontations, confluences, opening to the world, renewed humanism are references to this discussion, specifically focused on the role of Brazilian narrative in Latin-American narrative system.

PALAVRAS-CHAVE: Narrativa latino-americana, modernidade e modernização, poética da narrativa, narrativa brasileira no contexto latino-americano.

De manera mayormente conjetural, las notas siguientes se refieren a la posibilidad de sistematizar en el dominio de la literatura latinoamericana, el peculiar proceso de la narrativa hispanoamericana contemporánea, considerando, a la par, la dinámica de la narrativa brasileña. Si esta pretensión parece un lugar común por la invocación teórica de una comunidad cultural latinoamericana, en la práctica crítica han predominado los enfoques unilaterales, bien hispanoamericanos o brasileños, al intentarse una visión de conjunto de las tendencias hegemónicas de la narrativa de la alta modernidad.

En este contexto, el pensamiento de Antonio Candido representa un punto de giro por su contribución al entendimieno de la literatura latinoamericana en su totalidad contradictoria. Así en el caso de la nueva narrativa latinoamericana, Candido aduce que cuando es mencionada se piensa exclusivamente en la producción de los autores de lengua española, no pocas veces con sentido unificador simplista. Para completar el panorama se añaden algunos nombres, generalmente Guimarães Rosa y Clarice Lispector. Por otra lado, y hablando desde la perspectiva brasileña, se considera a los narradores del país como cosa aparte' ${ }^{1}$.

Aimée Gonzalez Bolaños é professora visitante da FURG.

${ }^{1}$ Ver: "O papel do Brasil na Nova Narrativa". Ponencia presentada en el seminario "The Rise of New American Narrativa”, Washington, 1979. 
A partir de estos cuestionamientos que formulados hace más veinte años, a mi modo de ver, no han perdido su actualidad, me pregunto cuáles son las tendencias dominantes en la narrativa latinoamericana y cómo se desarrolla la poética del arte de narrar en América Latina desde finales de los años 20 hasta la actualidad.

\section{LA NARRATIVA VANGUARDISTA:PRECURSORA DEL PORVENIR}

Según Alfredo Bosi las vanguardias latinoamericanas vistas de modo sincrónico como un sistema cultural definible en el espacio y el tiempo, no parecen otra cosa que un mosaico de paradojas: demasías de imitación y originalidad. Sin embargo, nuestros ismos están muy lejos de ser un epifenómeno, una "aplicación". En este sentido, una experiencia ejemplar resulta el modernismo brasileño con su metáfora clave "la devoración antropofágica que presupone a través de otra lógica, la incorporación de los atributos positivos del otro (...) Como una amalgama que se forma a partir de elementos diversos, la antropofagia conduce a una especie de composición, cuya esencia es, paradójicamente, la exteriorización de la diferencia que la consituye" ${ }^{2}$. Los escritores están ya en camino de aportar sus respuestas artísticas en esta experiencia tan intensa de renovación.

No obstante, este alcance de las vanguardias no se realiza plenamente en los marcos del vanguardismo. Distingue a los vanguardistas la crítica multiforme, coincidiendo más en los cuestionamientos que en el carácter de las respuestas, el sentimiento común de crisis y, sobre todo, el repudio de las enajenantes prácticas sociales de la modernización. De este modo se abre paso un nuevo concepto de comunidad creativa con conciencia creciente de su condición heterogénea y plural.

Una ojeada inicial a la narrativa de finales de los años 20 muestra una impresionante "constelación de renovadores", así llamados por Ángel Rama, en la que descuellan Miguel Ángel Asturias, Alejo Carpentier, Felisberto Hernández, Mário de Andrade, Oswald de Andrade, Roberto Arlt, Macedonio Fernández, Jorge Luis Borges, María Luisa Bombal, Arqueles Vela. La renovación narrativa se mueve entre el criollismo y los ismos europeos que en la práctica vanguardista latinoamericano no serán antípodas puros al ofrecer una original visión de los contactos interculturales. Como afirma José Carlos Mariátegui: "La nación vive en los precursores de su porvenir (...) Por esos caminos cosmopolitas y ecuménicos que tanto se nos reprochan, nos vamos acercando a nosotros mismos." Al entrar en contacto con estos sistemas creativos, los narradores buscan un arte nuevo que Carpentier justamente llama en su momento criollismo en profundidad, y también vanguardismo enraizado, patentizando su naturaleza híbrida, crítica y transicional, tal como puede apreciarse Macunaíma de Mario de Andrade y Ecue-Yamba-0 de Carpentier dos textos representativos de esta época.

${ }^{2}$ Raquel R. Souza: "Comentario sobre Manifiesto Antropófago, de Oswald de Andrade", hipertexto inédito para el CDROM Antología de textos fundantes para una teoria da Literatura Comparada InterAmericana, coord. Zilá Bernd, 1999. 
El arte de narrar se mueve del gesto iconoclasta destructivo hacia una incipiente tradición de oficio en el seno de una poética que enfatiza su carácter no representacional, empeñada en la superación de las visiones exterioristas del regionalismo tradicional y, a la vez, de la imagen evidentemente rara del surrealismo ortodoxo. Se critica y protesta de manera sui generis, propiciándose un nuevo contacto con la cultura popular que privilegia el acto de narrar, con creciente conciencia de su naturaleza y funciones. Tal parece que la narración se descongela, abriéndose a voces diversas y asumiendo nuevas significaciones lúdicas, paródicas, en las que el humor y la ironía resultan determinantes, para destruir, en fin, el contrato narrativo ilusionista finisecular. Los textos proclaman su carácter no verista, informe, han dejado de constituir una "forma" de acuerdo al persistente canon decimonónico para tornarse evanescentes, perdido el miedo a no parecerse a nada. Abocada a nuevas percepciones existenciales de un hombre moderno, en términos del nuevo siglo, con sus conmociones sociales y angustias intensamente personalizadas, la narrativa tematiza una identidad problémica, se busca a sí misma y busca, con sus quebradizas y elusivas ficcionalizaciones, un lugar en la historia, removiendo los cimientos de la temporalidad lineal, inevitablemente progresiva o regresiva, para acceder a una visión mucho más dubitativa e indagadora.

De este modo, la narrativa vanguardista que no muestra plena cohesión en sincronía, revela su identidad como vector de una parábola que atraviesa puntos y momentos diferentes. No es otra la certera conclusión de Alfredo Bosi. Vista como proceso y en su discronía, en ese movimiento destructivo y reconstructivo que la caracteriza, es que se muestran sus tendencias germinales, productivas hasta nuestros días. En consecuencia me atrevo a pensar que prácticamente toda la narrativa posterior está ya intuida o propuesta en esta experiencia de fundación.

\section{LA NARRATIVA DEL MEDIO SIGLO}

La narrativa de los años 40 y 50 pone de manifiesto una nueva fase en la transformación y búsqueda de nuevos códigos expresivos ahora con una propuesta más analítica y reflexiva. El reconocimiento de la riqueza de perspectivas instaurado por la narrativa precedente constituye un terreno propicio para la maduración de una poética que privilegia la realidad del arte y practica la literatura de los entrecruzamientos temporales y existenciales, ahondando en nuestros sincretismos. En relación directa a esta mirada reflexiva en profundidad, hacia lo constitutivo como constancia y cambio, particularmente sensible a la naturaleza de nuestra integración cultural de tan aportadoras simbiosis, se produce una apertura a lo universal. Con toda autenticidad esta tendencia universalizadora tiene su fundamento en una propuesta humanista, en un "humanismo cultural" a la búsqueda de una identidad amenazada, en la que dominan los descentramientos y pérdidas, y a la vez la necesidad de realización en la historia.

Trascendidas las posibilidades abiertas por la tradición regionalista que ahora emprende una nueva metamorfosis, según Angel Rama ${ }^{3}$, y experimenta una explosión

${ }^{3}$ Ver: Transculturación narrativa en América Latina, ed. Siglo Veintiuno, México D. F., 1982 
transfiguradora, en opinión de Candido; la narrativa opera con la dimensión ontológica, pero no como esencia metafísica, sino en el seno de la historia y la cultura propias, propuesta se integra con la mayor jerarquía estética en textos de Guimarães Rosa, Juan Rulfo, José María Arguedas, por ejemplo.

Quizás el signo distintivo del nuevo cauce del arte narrativo se encuentre en la espiritualización de sus coordenadas objetivas, predominando los estados de ánimo y de pensamiento, los modos de enfrentar la existencia y de vivir una cultura. De la misma forma se subjetiviza el cronotopo. El tiempo aparece como un hecho moral, expresivo de la búsqueda del hombre de sí mismo, que es siempre un suceso de la temporalidad, marcando esencialmente el discurso para convertirse en un enunciado metafórico de la mayor significación, centro de la meditación humanista.

Se pone de manifiesto una cosmovisión más lúcida y matizada que conjuga, desde un presente altamente problematizado, pasado y porvenir, con mayor comprensión del carácter altamente complejo de la existencia humana en nuestra cultura de aportadores mestizajes, hecha de avances y retrocesos. Esta búsqueda de identidad histórica, de historicidad existencial pudiera decirse, arrastra el peso de la historia, origen y semilla, pero también tendencia de futuro. Cuando tempranamente Borges invoca esos "recuerdos del porvenir", ofrece la clave para comprender la orientación de una narrativa que se revela como acto de fe humanista de tremendas potencialidades, donde pueden cruzarse todos los tiempos del hombre en el seno de su cultura.

Pero obviamente la historia que pone en juego la ficción no puede ser la oficial sacralizada, activándose la tarea de la desconstrucción de la historia petrificada, unida a la creación de nuevos significados. Así se privilegia la intrahistoria que aparece como presencia viva del vivir de la gente, presencia cuyo rastro, tal vez se perdería para siempre, si no quedara latiendo en la cultura. Precisamente este universo de lo humano en la cultura, constituye para los escritores de estas décadas un motivo principal y proyecto, sustentando una tendencia que mantiene toda su actualidad en el sistema de nuestra cultura artística.

Quiebra también la noción convencional de personaje, puesta en crisis por las vanguardias, como principio de mayor legibilidad del relato, que deviene un experimento, un sistema crítico y conjetural. El escritor se interroga como forma de recuperación de lo humano, de imponerse a la enajenación, de lo que resulta una narrativa de preguntas, de actitud autointerpretativa, abierta a múltiples interpretaciones y al debate. Ni la voz intradiegética u homodiegética, ni aún la que se presenta como extradiegética, podrán glosar el relato, instaurar monológicamente un sentido en estos textos que desde su propia generación promueven el protagonismo del lector.

La narración es vista desde su interior y en su transcurrir, al proclamarse cuento, relato, testimonio, documento. Avanza en el tejido de la metadiscursividad, de las relaciones intertextuales descubiertas, al intensificar su vínculo con el discurso antropológico, filosófico e histórico. El género, cada vez más conscientemente impuro y contaminado, se entrega a la crítica y al pensamiento, ganando en densidad 
reflexiva, sin dejar de ser una creación de la memoria imaginativa con sus elaborados juegos temporales y de lenguaje.

En este sentido resulta cardinal la estetización del habla puesto que al debilitarse la fábula, resulta privilegiada la enunciación. De este modo, y en su condición de lenguaje o mensaje escritural, son asumidos el coloquio y la oralidad, para entrar con fuerza el discurso del pueblo y la marginalidad. Inmersa en la heteroglosia, colecta hablas, voces, que responden a la pluralidad cultural, literaria y social, a menudo en conflicto, y las integra con el propósito del texto literario. Escritores como Lezama Lima, Carpentier, Guimarães Rosa, elevan el protagonismo del lenguaje, desarrollando su movilidad, flexibilidad y expresividad. Podría pensarse en la creación de un ideolecto estético, un código privado y personalísimo que trasciende el existente, de significativa coherencia y productividad poéticas, como otra de las más notables conquistas de la narrativa de estos años.

\section{LA NARRATIVA A PARTIR DE LOS AÑOS 60, HACIA UNA PLENITUD}

Como es bien conocido en los años 60 se produce un salto de calidad en la producción, difusión y promoción de nuestra narrativa, que ha sido llamada boom. Más allá de la debatida denominación, está el hecho de que la narrativa despliega sus potencialidades, integrándose la praxis de escritores establecidos en las décadas precedentes -acaso la apropiación retroactiva de Rulfo y Guimarães Rosa sea la de mayor impacto-, a una promoción más joven (Onetti, Sábato, Cortázar, Lezama Lima, García Márquez, Carlos Fuentes), unidos al redimensionamiento -casi siempre francés- de Borges, Carpentier, Jorge Amado, a los que se añade Clarice Lispector. Aparecen también, otros nombres relativamente nuevos como José Donoso, Guillermo Cabrera Infante, Mario Vargas Llosa. Ellos, en su conjunto, producen una narrativa que patentiza tanto el desarrollo intrínseco del género, como un conjunto de mecanismo publicístícos, promocionales y editoriales. Coincide, por tanto, el movimiento que Carlos Fuentes identifica como "nueva novela latinoamericana" con el boom, momento creativo en el que ciertamente marcan el paso los escritores hispanoamericanos, si bien influyente en el reconocimiento y promoción internacional de la narrativa brasileña.

En esta "década prodigiosa" habría que considerar, en primer término, la continuidad de lo que la narrativa viene gestando desde finales del 20, aunque una zona de la producción no pueda escapar de ciertas normas de mercado que condicionan la reiteración de los códigos expresivos, con la tendencia a un nuevo tipo de exotismo cosmopolita más enmascarado e intelectualizado que manipula las visiones americanista, modelo de narrativa que después será repetido hasta el agotamiento por lo epígonos del "realismo mágino". Pero no es esta la dimensión que distingue al momento y ciertamente quedan obras que hacen época en la literatura contemporánea: Sobre héroes y tumbas, El siglo de las luces, La ciudad y los perros, La muerte de Artemio Cruz, Rayuela, Paradiso, Cien años de soledad, entre otras, y sin intentar el catálogo. 
La narrativa se carga de sentido mítico, alegórico y poético en su peculiar búsqueda de identidad, que concierne al género humano, pero también expresiva de rasgos sustantivos identificadores en el sistema de la cultura propia. La obra está marcada por esa identidad, fracaso o proyecto, expresión de una experiencia subjetiva, con una fuerte, no necesariamente evidente, referencialidad histórica. En vínculo profundo con las conquistas de la narrativa precedente, se trata de una historia interior, antropomorfa, en la que cada figura puede ser también simbólica. Predomina un tipo de omnisciencia en la voz narradora de acusado sentido de las fuerzas y pulsaciones sociales, capaz de totalizar el saber comunitario.

Con fuerza se proclama una voluntad totalizadora del mundo de la vida americana, como suma ecuménica que integra el caudal de discursos sobre el Continente, de modo que la narrativa se afirma y cobra plena conciencia de sus contextospraxis, punto de vista que ejemplarmente Alejo Carpentier por estos años conceptualiza. Transgrediendo los presupuestos de la narrativa de "contenido social", de "denuncia", el escritor combina la experiencia subjetiva personal y la colectiva humana. De aquí, la imposibilidad de encuadrar los textos en las opciones tradicionales de narrativa social o personal, de escritura popular o erudita, como certeramente apunta Candido pues "a tomada de partido ou a denúncia são sustituidas pelo modo de ser ou exisir, do ângulo da pessoa ou do grupo."

Cieramente esta narrativa de los contextos necesita entender, pero también trascender. Cifra el escritor la experiencia histórica y con ella sus fundamentos ontológicos, a la búsqueda de salida y centro. En otro texto ejemplar de este tiempo literario, José Lezama Lima hace variaciones sobre el tema del laberinto, significativamente actualizado por la cultura de la modernidad. En el interior de una concepción general del arte como acto poético de penetración en la naturaleza que crea una sobrenaturaleza "El laberinto es un proyecto de lo difícil y renuente (...) Ejercicio de combate dentro del combate. Identificados laberinto y narrativa, Lezama apunta hacia una tendencia humanista dominante en la escritura de estos años que postula una imagen del hombre que es creado y creador incesamente. El texto narrativo resulta de forma natural, genésico, alegórico, críptico, omnicompresivo, no solo mítico, sino productor de mitología, en la acepción de Lotman que corresponde a la modelización total de un universo de ficción. De aquí sus mundos posibles coherentes, de impresionante y singular historicidad que asume significados universales, acaso Macondo el paradigma epocal.

Este carácter diríase proteico, el texto no imita, crea, transforma la escritura en un juego productivo del trabajo sobre lo literario, puede encontrarse también con valor modélico en los textos de Lispector donde, al decir de Antonio Candido, el tema y ël instrumento verbal se justifican por el hecho de producir una realidad propia con su inteligibilidd específica, "não se trata mais de ver o texto como algo que conduz a este ou aquele aspecto do mundo ou do ser; mas de lhe pedir que crie para nós um mundo ou o mundo".

Inmersa en una continua búsqueda expresiva, asimilando lo más productivo 
del patrimonio narrativo mundial, el narrador apela a su "biblioteca imaginaria" para acceder a una comprensión intertextual, literaturizada, en tanto que el referente social se hace más palpable en los múltiples textos de la cultura. Volcada a la innovación, que el propio Candido reconoce como línea dominante de la narrativa brasileña de vanguardia artística y amargura política, los textos se descubren como una invención poética del mundo americano, socialmente estremecido, heterogéneo y desmesurado.

La novela y el cuento se descubren como obras de la lectura, fenómeno crítico y escritural, meditan sobre sí mismas, "el lector salta sobre el autor, nuevo hombre del Zoar, y forman un nuevo centauro", potenciándose, como en el vanguardismo, los efectos sociales del texto. El lector productivo interpreta y ordena en el laberinto plurívoco del discurso y la composición, enfrentándolo a formas literarias envolventes, de gran apertura y amplitud como las concepciones hiperbólica mítica, épica y alegórica, que no en pocos casos aspiran a la refundación literaria del mundo de la vida.

En el interior de este proceso ininterrumpido de modernización, a partir de los años 70, sin que pueda hablarse de un grupo, ni de una total identidad estética, mucho menos programática, comienzan a manifestarse otras tendencias, ostensibles un tanto emblemáticamente en la obra de Augusto Roa Bastos y Manuel Puig, también en los textos de Luisa Valenzuela, Juan José Saer, Abel Posse, Isabel Allende, Antonio Skármeta, Fernando del Paso, Elena Poniatowska, Angeles Mastretta, Severo Sarduy, Reinaldo Arenas, Lisandro Otero, Nélida Piñón, Lya Luft, Rubem Fonseca, João Ubaldo Ribeiro, entre otros. Habría que tener en cuenta, además, y no como un factor secundario, los nuevos textos narrativos de Carpentier, García Márquez, Carlos Fuentes, Lispector, Cortázar, Vargas Llosa.

Esta práctica narrativa, con frecuencia denominada postboom en Hispanoamerica, estará relacionada de manera más explícita con la poética del posmodernismo, sobre todo en lo que concierne a la "localización, fragmentación, horizonte pequeño, cierto minimalismo" y un pretentido retorno a la "espontaneidad". Significativamente para algunos críticos marca un giro total, mientras para otros implica un desarrollo más abierto de potencialidades presentes en los maestros de la narrativa precedente dentro de lo que en los años 80 ha sido llamado metaficción.

Para Juan Manuel Marcos ${ }^{4}$ escritores vinculados al boom: Borges, García Márquez, Vargas Llosa (los minotauros) conciben la realidad americana como un caos sin salida, se encierran, por tanto, en el culto del lenguaje, confiriéndole a la obra un carácter reificado. A ellos se opone la narrativa de los 80 (la de los cervantistas) que redescubre dos importantes recursos de clara ascendencia bajtiniana: la parodia o carnavalización intertextual para pulverizar los valores establecidos y la potenciación de la naturaleza dialógica de la ficción, buscando la recreación artística de algunos géneros populares. Como puede apreciarse este reduccionismo, no exento de notas caracterizadoras sugerentes, instaura una peculiar visión de la narrativa sobre la base de arquetipos que respondiendo a un programa axiológico hiperestructurado,

${ }^{4}$ De García Márquez al postboom, p. 81, ed. Orígenes, Madrid, 1986 
tiende a desvirtuar la significación cultural y artística de los textos.

Otro acceso epistemológico puede hallarse en Ángel Rama cuando señala que los novísimos (años 70) operan un reingreso a la historia y al realismo con un "discurso del verosímil", ajustado al tiempo contemporáneo, lo que permite la recuperación de maestros como Carpentier, Onetti, Rulfo: "La búsqueda integradora fue, como dijimos, también un retorno a la historia, una recuperación de las tradiciones propias dentro de una perspectiva modernizadora que se aprendió en los mayores que hicieron la nueva narrativa latinoamericana." 5

En este orden de pensamiento Jorge Rufinelli destaca que puntos de vista como los de Skármeta y Giardinelli, por ejemplo, suponen más un distanciamiento estético e ideológico que un rompimiento total en la práctica creativa. Los narradores que irrumpen en los años 80 , sin obviar lo específico de sus poéticas personales "Lo que para mí expresan, más que una rotunda diferencia, es una voluntad de cambio, de no aceptar los laureles de los años 60, de continuar hacia adelante y hacer respetar sus individualidades." Y a continuación añade una observación esclarecedora: "Son también un signo de la crisis de crecimiento de una generación a la que preceden padres famosos. En todo caso, lo más sensato sería concluir a este respecto que después de los 60, el modelo propuesto por la literatura latinoamericana fue admirado y seguido de una manera condicional y crítica."

Desde esta perspectiva, sin absolutizar las rupturas, me parece destacable el auge de la autorreflexividad en textos que de modo intenso y sostenido exploran, tematizándolos, sus niveles metalinguísticos, metaliterarios y metatextuales, para ofrecer un rico tejido interdiscursivo, a menudo lúdico, intertextual y transgenérico, entregados sin restricciones a la heteroglosia. Así. la narrativa de estos últimos años puede constituir un ensayo de reflexión sobre sus instrumentos y problemático sentido, también de la tradición textual en que se enmarca, cuestionando a menudo los tópicos del realismo mágico, del folclorismo, del primitivismo cultural. La obra narra su historia, su hechura, concentrada cada vez más en el propio acto de la escritura que se autorrepresenta como lectura, a la vez que se desacraliza la instancia autoral como sumo protagonista del evento creativo.

En esta concepción transgresora, los textos son compuestos de modo sistémico por oposición y mezclas. Se trabaja a fondo las posibilidades comunicativas del montaje, sobre todo de las diferentes formaciones discursivas examinadas en su interrelación y a fondo, lo que pone de manifiesto el carácter esencialmente heterogéneo, multiforme y plurívoco del universo narrativo en correspondencia con una determinada visión del mundo de la vida. La narración se rebela contra las camisas de fuerza del discurso logocentrista de la cultura occidental que clasifica, organiza, resume los fenómenos del mundo real, sin explicar la naturaleza de las cosas.

Como certeramente apunta Candido dominan las tendencias desestructurantes, los textos envuelven y agreden al lector, evidenciando una naturaleza indefinible que aprovecha todos los tipos de discurso "romances que mais parecem reportagens;

${ }^{5}$ Novísimos narradores en Marcha (1964-1980), p. 18 , ed. Marcha, México D. F., 1981 
fotomontagens; autobiografias com tonalidade e técnica de romance; narrativas que são cenas de teatro; textos feitos com a justaposição de recortes, documentos, lembranças, reflexões a toda sorte" con predominio de la no ficción, punto de vista que también Rama suscribe, y que la narrativa de estos últimos años corrobora, basta recordar Noticia de un secuestro de García Márquez, Paula de Isabel Allende, O rio do meio de Lya Luft.

La narración descentrada y la dispersión de la conciencia de los personajes, incluido narrador y narratario, la fragmentación del discurso como expresión del gusto por los segmentos, lo discontinuo y transformacional, viene a ser una forma natural, constitutiva, pertinente. Allí, en el universo de la narración, proliferan las alternativas, para fundarse un espacio virtual abierto a múltiples posibilidades. También el lenguaje sigue transformándose. El escritor juega con los estilos linguísticos, puede trabajar tanto el simulacro de un estilo barroco cultista, como la naturalidad del coloquio, o el lenguaje de los medios masivos de comunicación (cine, telenovelas, comics, narrativa trivial, etc.), a más del de la música y las diversas manifestaciones de la cultura popular, para terminar incorporándolos, más allá de la parodia, en una proceso artísticamente productivo de canibalización, de cruces, confrontaciones y contaminaciones interdiscursivas, perdida la conciencia de la subversión, cerca ya de la indiferencia, marcando una actitud más libre y desprejuiciada.

Estas prácticas hacen pensar no solo en la potenciación de renovados sistemas estéticos comunicativos, significativamente afines a la vanguardia, sino también en un renovado humanismo, a veces hiperrrealista, otras fantástico, generalmente minimalista, de énfasis en la relatos pequeños, ajeno al esencialismo y a los significados trascendentes, después de las consagraciones del realismo figural y simbólico, de las dimensiones míticas y mágicas de los maestros de la nueva novela. Como Skármeta reconoce "donde ellos se distancian abarcadores, nosotros nos acercamos a la cotidianidad con la obsesión de un miope". Humor desmitificante, sentido lúdico, gusto por las simulaciones, la desmesura, los grotescos y los mundos alucinados, pero en un relativo tono menor y a partir de una visión desde el individuo, desde la personalidad descentrada que da cuenta de su crisis telelógica de trascendencia y destino; todo ello alterna o convive con una actitud contestataria, antiautoritaria y desacralizadora que, no en pocos casos, aspira a nuevas fundaciones como expresión de la vigencia de los proyectos desalienadores.

Y a manera de constante, una subjetividad fuerte y en conflicto que asume sus contradicciones, sin pretender convertirlas a priori en clave de un hipotético y atemporal ser, bien génerico o latinoamericanos. De este modo la búsqueda de identidad resulta una experiencia cada vez más traumática, aunque aportadora, incorporándose con fuerza la problemática histórico-cultural en el sentido más amplio y, a la par, la de la escritura, que arrastra el debate sobre la imagen del autor. Evidentemente el autor como instancia de la ficción se pregunta sobre su autoridad y legitimidad no solo artística, sino también social, humana, una vez que ha dejado de ser la suma instancia productora de la textualidad. 
Con significativa insistencia, la narrativa propone una imagen del ser humano atravesada por la crisis de valores, expresiva de la situación espiritual de nuestro tiempo, que indaga en el universo de la marginalidad, la diferencia y la otredad, que significa no solo por sus presencias, sino también por sus ausencias; acaso una explicación primera de la importancia del discurso de las minorías étnicas y sociales en estas últimas décadas, de la tematizaciòn de la experiencia erótica y, en particular, de la homosexualidad, tan distintiva de la narrativa actual. En este contexto toma una significación especial el discurso femenino en su desconstrucción del discurso homocéntrico, al fundir voz y escritura en una práctica creativa crítica y subversiva de las estructuras sociales en su sentido más amplio.

La lectura, muy diferente a la de los paradigmas de las fases tempranas de la modernidad, no se encamina a verificar la sabiduría o la coherencia interna del discurso, sino a explorarlo como manera de entender el mundo, de interpretar la historia, de descubrir los valores predominantes en una cultura. En no pocos casos el texto se constituye en virtud de una estrategia conterreferencial de múltiples y proliferantes sentidos: aporías, versiones, variantes casi siempre contradictorias, buscando una nueva manera de significar, de aludir a la referencia. Tal vez por ello Manuel Durán asegura que los narradores reinventan a América, la redefinen, mezclando una experiencia real e inventada ${ }^{6}$. Sin embargo, la imaginación al encarar los procesos tramadores de la historia no se limita al revisionismo desconstructivo: sin la memoria histórica no hay identidad posible. Por tanto la lectura e interpretación de una escritura, aún de la "duda" y la "sospecha", lleva al movimiento de reconstitución, también augurado por la vanguardia, aunque altamente problematizado, que se fundamenta en un humanismo práctico, antiespeculativo, de notable persistencia en la cultura espiritual latinoamericana, que no debe ser indentificado con la renuncia al conocimiento intelectualizado. Desde Borges, habrá que reconsiderar, a su vez, la duda productiva, capaz de instaurar nuevos horizontes interpretativos y pragmáticos.

De aquí que lo nuevo no sea exactamente "la recuperación del pasado, sino el intento de otorgar sentido a la aventura del hombre americano mediante bruscos cortes en el tiempo y el espacio que ligan analógicamente sucesos dispares, sociedades disímiles, estableciendo de hecho diagramas interpretativos de la historia", en abierto debate con una temporalidad histórica, y su consecuente imagen humana, conclusiva, ontoteleológica, hiperestructurada. Más bien debiera apuntarse una conciencia mayor de la discontinuidad de la historia, de sus cortes, vuelcos e intermitencias, sin minimizar sus retrocesos; punto de vista que no necesariamiento deberá ser rastreado en el posmodernisno metropolitano, sino en el pensamiento más cercano de un Octavio Paz, o en las ficciones de Carpentier y Borges que con su visión precisamente "analógica" de la temporalidad, contribuyeron decisivamente a instaurar una perspectiva multidireccional de los tiempos históricos, del tiempo humanizado, y con ello una visión mucho más reveladora de las infinita complejidad humana.

\footnotetext{
6“La nueva novela hispanoamericana" en Historia y ficción en la narrativa hispanoamericana, p. 47, ed. Monte Avila, Caracas, 1989.

${ }^{7}$ Angel Rama. Novísimos..., ob. cit., p. 20.
} 
Si en verdad no faltan notas autodestructivas, absolutizadoras de la desconstrucción y nihilistas en la hora literaria actual, con una visión más integral de la narrativa latinoamericana, pudiera suscribirse el criterio de Octavio Paz cuando afirma que "La modernidad es sinónimo de crítica y se identifica con el cambio, no es la afirmación de un principio atemporal, sino el despliegue de la razón crítica que sin cesar se interroga, se examina y se distingue por renacer de nuevo."

Autoconsciente desde su condición estética, de su hibridez y alteridad, de la necesidad de actuar en el mundo de la vida, la narrativa sigue interrogándose. Con su inusitada temporalidad, en medio de las contradicciones y paradojas de su medular humanismo, contribuye a la creación de una identidad moderna polémica y disputada. Como dice Lezama Lima, si se mira por un extremo del anteojo, la narrativa es sorprendida por una plenitud: "Mira por el otro extremo del anteojo y es ahora una plenitud sorprendida por una novela."

Para terminar, quisiera enfatizar que la mirada de conjunto y en movimieto de la narrativa en sus tendencias hegemónicas, resulta una necesidad de primer orden para el entendimiento de nuestra literatura. Siendo así, levanta cuestiones cardinales para el debate. Hipotéticamente, cito algunas: La envergadura y vigencia estéticas, sobre todo a nivel de poética narrativa, de la experiencia vanguardista/modernista que marca el inicio de un proceso de búsqueda de nuevas estrategias comunicativas abierto hasta nuestro días. El gran alcance estético y cultural de de la narrativa latinoamericana de los años 40 y 50 (El reino de este mundo, Pedro Páramo, Grande Sertão: Veredas) que forman parte de un corpus narrativo coherente en su diversidad, visión generalmente referida al boom narrativo posterior. Por último, la dialéctica de continuidad/ruptura como una constante mayor de la renovación narrativa desde los años 20 , ostensible también en la unidad contradictoria de boom/postboom, que marca una época creativa de notable repercusión artística.

En el abordaje de estas problemáticas, es importante formular las preguntas y buscar las respuestas desde la perspectiva propia, en contraposición a las tendencias homogeneizadoras predominantes en la crítica europea y norteamericana de estos últimos años, y reparando, sobre todo, en la totalidad contradicotira de nuestra literatura, de nuestra narrativa en este caso, que no puede desconocer sus cambios epocales y el carácter plural de su constitución.

Desde la experiencia tan controvertida de la vanguardia en su momento hasta el presente, la narrativa latinoamericana participa de manera intensa y original en la lógica de la cultura moderna, también posmoderna, sin perder la conciencia de sus contextos socioculturales, de lo específico de su identidad, que tampoco puede desgajarse del curso de la cultura universal, relación que ha sido reconocida como constante en el seno de nuestra experiencia poscolonial. Existe en las letras continentales un movimiento interno, también matizado por poderosos factores extraliterarios, que paulatinamente va integrando una práctica creativa que nos identifica en los fecundos contactos interculturales, en la sintesis integradora de influencias múltiples.

De aquí parte una productiva tradición que privilegia las confrontaciones, de 
confluencias creadoras, que puede considerar la cultura mundial como patrimonio. La literatura latinoamericana se realiza en su apertura al mundo, en una relación interactiva continua, en un juego permanente de asimilación y rechazos, modo peculiar, aunque no exclusivo, de autentificarse en el contexto mayor de la internacionalización del trabajo intelectual y artístico, inherente a la cultura moderna en su totalidad.

También destacaría, la significación de la propuesta humanista de la ficción narrativa, en su fuerza, anticonvencionalidad y persistencia, que desde Borges, pasando por Clarice Lispector, hasta Severo Sarduy -y utilizo estos nombres debatidos con toda intención- no ha perdido, por el contrario ha diversificado y profundizado su sentido humanizador. Así la narrativa, afincada en la diversidad de culturas, ha constituido un discurso orientado hacia el descubrimiento de sí y del mundo de la vida, entregada a las búsquedas de su ser histórico y existencial, también a las de su propia naturaleza como escritura artística, de ahí sus poderosas realizaciones estéticas, patrimonio identificador con el que participa, legítimamente, en el complejísimo tejido de nuestro tiempo.

\section{BIBLIOGRAFIA}

BARBOSA, Heloisa Goncalves. Boom or Transformation by Translation? Latin American Literature en English. Transit Circle, Porto Alegre, n.1, p.174-190, 1998.

BOSI, Alfredo. La parábola de las vanguardias latinoamericanas. En: Las vanguardias latinoamericanas. Textos programáticos y críticos de José Schwartz. Madrid, Cátedra, 1991.

CARPENTIER, Alejo. Problemática de la actual novela latinoamericana. En: Tientos $y$ diferencias. La Habana, UNEAC, 1966.

ECHEVARRÍA Roberto González. Miyth and Archive. Toward a Theory of Latin American Narrative. Cambridge/New York, Cambridge University Press, 1990.

FIRMAT, Gustavo Pérez. Idlee Fiction. The HispanicVanguardia Novel, 1926-l934. Durhan, Duke University Press, 1992.

LIMA, José Lezama. Cortázar y el comienzo de la otra novela. En: La cantidad hechizada. La Habana, UNEAC, 1970.

MEJÍA, Manuel Velázquez. Identidad latinoamericana. México, Universidad Autónoma del Estado de Toluca, 1993.

PAZ, Octavio. Los hijos del limo. Barcelona, Seix-Barral, 1989.

RUFINELLI, Jorge. Los años 80: ¿ingreso a la posmodernidad? Nuevo texto crítico. Stanford, n.37, v.6, 2do semestre, 1990.

SKÁRMETA, Antonio. Al fin y al cabo, es su propia vida la cosa más cercana que cada escritor tiene para echar mano. En: Más allá del boom: literatura y mercado. México, D.F., Angel Rama, Ediciones Marcha, 1981. 